\begin{tabular}{ccc}
\hline & International Journal of Engineering \&Technology, $7(3.12)(2018) 403-406$ \\
SPC & Website www.sciencepubco.com/index.php/IJET \\
Research paper & Technology \\
\hline
\end{tabular}

\title{
Strength Properties of Recycled Aggregate Concrete Treated with Low Concentration Acetic Acid
}

\author{
Naveen Kumar $\mathbf{N}^{1}$, ParthibanKathirvel ${ }^{2 *}$, Murali $\mathbf{G}^{3}$, Saravana Raja Mohan Kaliyaperumal ${ }^{4}$ \\ School of Civil Engineering, SASTRA Deemed University, Thanjavur, India \\ *Corresponding Author Email: ${ }^{2}$ parthiban@ civil.sastra.edu
}

\begin{abstract}
Recycled concrete aggregates have inferior qualities compared with the natural aggregates, mainly attributed due to the porous nature of the attached cement mortar. In previous researches treatment of recycled aggregates are done using concentrated nitric acid, hydrochloric acid and sulphuric acid but they showed less view on acetic acid which is eco-friendly and also removes more adhered mortar in the recycled aggregates. The aim of this investigation is to determine the strength characteristics of Recycled Concrete Aggregates(RCA) which have been treated using low concentration acetic acid solution (1\% solution and with immersion duration of 1 and 3 days). The treated aggregates are tested for compressive strength, split tensile strength, water absorption, impact strength and bond strength for a curing period of about 7 and 28 days.
\end{abstract}

\section{Introduction}

Concrete is used almost everywhere mankind has a need of infrastructure. In developing countries like India there is a huge requirement for construction materials and also more construction debris is generated every year, which became a serious issue as it acquires huge space as well as pollutes the environment. Recycling of this debris as recycled concrete aggregates help to solve environmental impacts. The researchers say that recycled aggregate requires more water for the same workability of natural aggregate concrete because of the mortar attached in the aggregate [1]. Due to the mortar attached in the aggregates it has some inferior qualities present with the natural aggregates. The recycled aggregate is highly porous in nature due to the adhered mortar and also it introduces some undesirable properties to the recycled aggregates especially higher crushing value, higher water absorption and less strength [2-4]. Due to this properties the recycled aggregates has to be treated and viable way to improve the quality of concrete.

A few methods have been developed to treat the recycled aggregates are chemical treatment, freeze and thaw effect and thermal treatment [5-12]. From all those methods they all have some drawbacks like in thermal treatment $[10,11]$ they release large amount of carbon-di-oxide, in freeze and thaw effect[6,7] even the mortar is removed about $70 \%-80 \%$ but the process duration is more. Coming to the chemical treatment $[5,8,9]$ low concentration acid solution is used (nitric acid, hydrochloric acid and sulphuric acid) where they are immersed for certain duration so that mortar attached to the recycled aggregate is removed. Treatment using this acid poses a threat to safety of workers and also causes durability issues to concrete.

In order to overcome the existing chemical treatment methods use of low concentration acetic acid solution is proposed in this investigation so that good quality recycled aggregates can be produced and it can be free from the detrimental ions [13]. It is cleaner, safe and causes no hazard to the safety of workers.
Addition of mineral admixtures may also interpret with the concrete rheological properties like performance, strength and workability [14]. The major objective of this paper is to confirm optimum dosage period of concentrated acetic acid to treat the recycled aggregates and to determine the optimum replacement level of natural aggregates with recycled aggregates on the strength characteristics of concrete [15].

\section{Experimental Investigation}

\section{Materials}

Ordinary Portland cement (OPC) grade 43 was used as the main binder for concrete with specific gravity of about 3.15 , which is locally available in Thanjavur, India. The coarse RCA are collected from the nearby demolished building and they are been crushed to respective sizes. The fine aggregate used is manufactured sand which is also locally available with a specific gravity of 2.81. The chemical admixture used is polycarboxylate based super plasticizer which is a highly water reducing agent.

\section{Process of Treatment}

RCA samples are oven-dried and then they are immersed in acetic acid solution of a concentration of $1 \%$ at ambient temperature with 1 and 3 day immersion duration. At the time of treatment the acetic acid react with the recycled aggregates and emits carbondioxide gas forming gas bubbles as shown in fig.1.a. The sample is remained undisturbed for 1 and 3 days. After the specified immersion duration the aggregates are taken out and they are placed in hot air oven for a period of $3 \mathrm{~h}$ and then kept at room temperature until the aggregates becomes cool. The treated aggregates are shown in fig.1.b. Then, the sample is shifted to Los angel's abrasion testing machine and 50 complete rotations and they are sieved in $12.5 \mathrm{~mm}$ sieve to separate fine aggregate from the coarse aggregate. Only the Coarse RCA's are used for the mix. The material properties of RCAs are mentioned in Table 1 


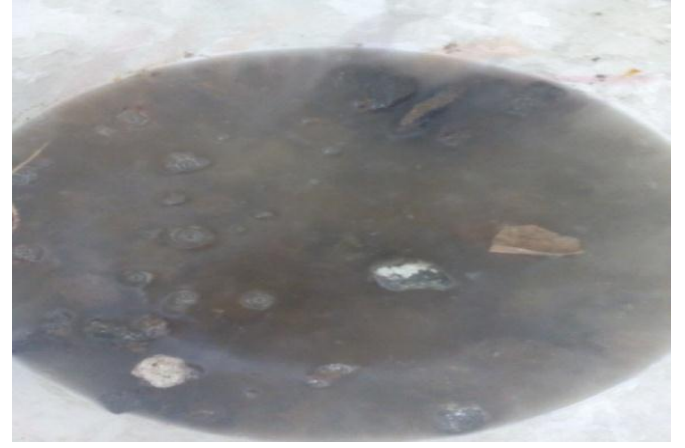

(a)

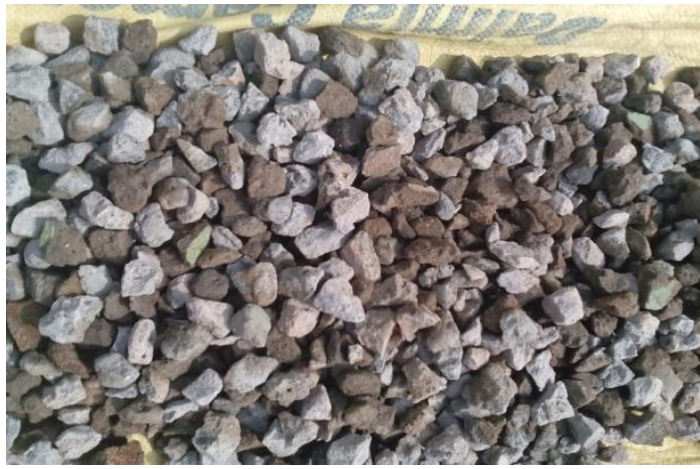

(b)

Fig. 1(a): Recycled aggregates under treatment, (b) Treated Recycled Aggregates

Table 1: Test investigation of Natural aggregates and Recycled aggregates

\begin{tabular}{|l|l|l|l|}
\multirow{2}{*}{$\begin{array}{l}\text { Test investigation } \\
\text { of aggregates }\end{array}$} & \multirow{2}{*}{$\begin{array}{l}\text { Natural } \\
\text { Aggregates }\end{array}$} & $\begin{array}{l}\mathbf{1} \text { immersion } \\
\text { immen }\end{array}$ & $\begin{array}{l}\mathbf{3} \text { day } \\
\text { immersion }\end{array}$ \\
\hline Abrasion test & $2 \%$ & $5.17 \%$ & 5.60 \\
\hline Water Absorption & $0.5 \%$ & $2.94 \%$ & $2.25 \%$ \\
\hline Specific Gravity & 2.73 & 2.45 & 2.41 \\
\hline $\begin{array}{l}\text { Aggregate Impact } \\
\text { Value }\end{array}$ & $16.12 \%$ & 39.40 & 37.50 \\
\hline $\begin{array}{l}\text { Aggregate Crushing } \\
\text { Value }\end{array}$ & $20.14 \%$ & 28.40 & $25 \%$ \\
\hline Fineness Modulus & 7.51 & 8.29 & 8.2 \\
\hline
\end{tabular}

From the test investigation it is come to know that the immersion duration does not show a major difference in the material properties of the aggregates. There is also no loss in weight difference from the both the samples of treatment. Hence it is sufficient to do concrete mix $1 \%$ acetic acid treated recycled aggregates with one day immersion period.

\section{Mix Proportion}

The mix design is done as per IS code 10262:2009 [16] and grade of concrete is M40. Constant effective water cement ratio of 0.40 is used for all the mix proportions as shown in Table 2. Concrete cubic specimens of size $100 \mathrm{~mm}$, cylinders of diameter $100 \mathrm{~mm}$ and $200 \mathrm{~mm}$ height, cylinders with diameter $150 \mathrm{~mm}$ diameter and $60 \mathrm{~mm}$ height and cube of size $150 \mathrm{~mm}$ with $16 \mathrm{~mm}$ diameter steel rebar were prepared for compressive strength test, splitting tensile strength, impact strength, bond strength and water absorption test The Recycled aggregates are replaced with the natural aggregates at a percentage of about $25 \%, 50 \%$ and $75 \%$ by the weight of total aggregates.

Table 2: Mix proportion of Recycled Aggregate Concrete with Natural Aggregate

\begin{tabular}{|l|l|l|l|l|l|l|}
\hline Mix & \multirow{2}{*}{$\begin{array}{l}\text { RCA } \\
\text { No }\end{array}$} & $\%$ & \multicolumn{4}{|l|}{ Mass in $\mathbf{~ k g} / \mathbf{m}^{\mathbf{3}}$} \\
\cline { 3 - 7 } & Cement & Sand & NA & RA & Water \\
\hline M0 & 0 & 341.25 & 901.23 & 1136.89 & 0 & 136.50 \\
\hline M1 & 25 & 341.25 & 901.23 & 852.67 & 284.22 & 136.50 \\
\hline M2 & 50 & 341.25 & 901.23 & 568.45 & 568.45 & 136.50 \\
\hline M3 & 75 & 341.25 & 901.23 & 284.22 & 852.67 & 136.50 \\
\hline
\end{tabular}

\section{Results and Discussions}

\section{Compressive Strength Test and Splitting Tensile Test}

The concrete cubic specimens and cylinders were casted conforming to the code[17]. The specimens were casted in order of the mix proportion as shown in table 2 . The concrete is mixed using mixture machine and then molded into cubes of size $100 \mathrm{~mm}$ and cylinders with $100 \mathrm{~mm}$ diameter and $200 \mathrm{~mm}$ height. The specimens are kept in curing for a period of 7 and 28 days. The test results are shown in Table 3. From the results obtained we can see that the compressive strength will attain maximum when the RCA is replaced with NA up to $50 \%$ when compared to the other replacement percentage. In the Splitting Tensile Strength the tensile strength is increasing up to $25 \%$ replacement with natural aggregates. This is because the acid treated recycled aggregates obtained good quality and attached mortar is removed from the aggregates.

Table 3: Compressive and Split Tensile Strength Test Results in N/mm²

\begin{tabular}{|c|c|c|c|c|}
\hline \multirow{2}{*}{ Mix } & \multicolumn{2}{|c|}{$\begin{array}{c}\text { Compressive strength } \\
\text { test }\end{array}$} & \multicolumn{2}{c|}{ Splitting Tensile Strength } \\
\cline { 2 - 5 } & $\mathbf{7}$ days & $\begin{array}{c}\mathbf{2 8} \\
\text { days }\end{array}$ & $\mathbf{7}$ days & $\mathbf{2 8}$ days \\
\hline M0 & 31.96 & 45.6 & 3.62 & 4.5 \\
\hline M1 & 37.7 & 47.2 & 3.74 & 4.98 \\
\hline M2 & 38.6 & 50.4 & 3.59 & 4.17 \\
\hline M3 & 29.32 & 39.5 & 2.8 & 3.45 \\
\hline
\end{tabular}

\section{Water Absorption Test}

The Water Absorption test is done for concrete cubic specimens of size $100 \mathrm{~mm}$ for curing period of 7 and 28 days and their results are shown in Table 4 and fig.2. Normally, Recycled aggregate has more water absorption when compare to that of natural aggregates due to the mortar present in recycled aggregates. From fig. 4 it is represented graphically that more the percentage replacement of RCA with NA then the water absorption will be more due to some of the mortar present in the aggregate and their porous nature. When the period of curing increases the water absorption also increases.

Table 4: Water Absorption Test Results in percentage

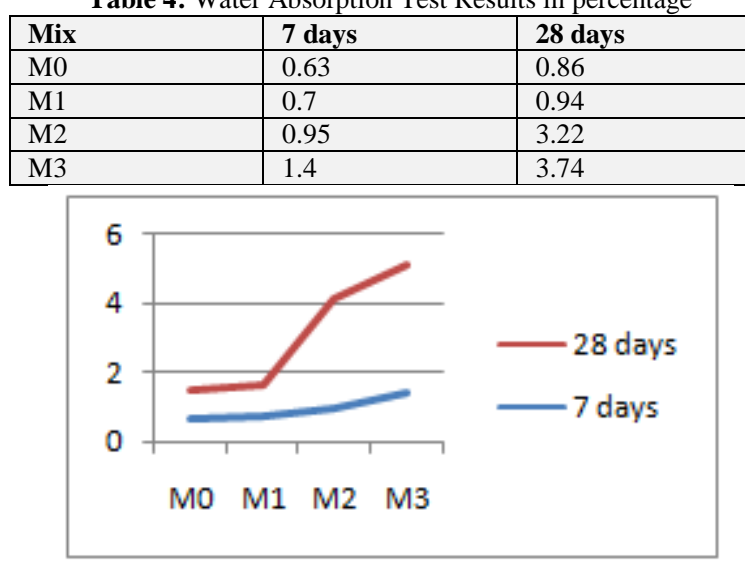

Fig. 2: Water Absorption Test

\section{Bond Strength Test}

The Universal Testing machine is used to test the Bond Strength between the Concrete and Steer rebar. The cube is casted using the $16 \mathrm{~mm}$ diameter rod which is placed at the center and penetrated to bottom for $10 \mathrm{~mm}$. The length of the rod can be up to $80 \mathrm{~cm}$ in length. The casting and test procedure is done as per IS 2770 regulations [18]. The Peak load and the bond strength of the specimens are shown in the Table.5. The Bond Strength is calculated using the equation.

Bond strength $=\frac{P}{\pi d l}$ 
Where, $\mathrm{P}=$ Peak load in $\mathrm{N}, \mathrm{d}=$ diameter of the rebar, $\mathrm{l}=$ embedded length of the specimen

Table 5: Bond strength Test of concrete cube specimens in $\mathrm{N} / \mathrm{mm}^{2}$

\begin{tabular}{|c|c|c|}
\hline \multirow{2}{*}{ Mix } & \multicolumn{2}{|c|}{ Bond strength } \\
\cline { 2 - 3 } & $\mathbf{7}$ days & 28 days \\
\hline M0 & 6.45 & 5.04 \\
\hline M1 & 6.39 & 5.15 \\
\hline M2 & 5.34 & 5.55 \\
\hline M3 & 8.78 & 8.22 \\
\hline
\end{tabular}

The bond strength for the recycled aggregate concrete with natural aggregate is attained high for the replacement percentage of $75 \%$ with the natural aggregates. This is due to the poor bonding with aggregate and the rebar and also when the period of curing increases the bond strength tends to decrease due to corrosion in the bar.

\section{Impact Strength Test}

Cylindrical Specimens of size $150 \mathrm{~mm}$ in diameter and $60 \mathrm{~mm}$ height are used for impact energy test as per ACI 544 codal provisions [19]. The test setup is shown in Fig.5 which consists of 2 metal balls of weight $3.56 \mathrm{~kg}$ and $2.86 \mathrm{~kg}$ and impact base. The ball with more weight is blown at a height of $571 \mathrm{~mm}$ from the top of small ball and placed above the specimen, this procedure is repeated until the sample is attained to first crack and the failure and number of blows is noted. The impact energy absorption of each specimen was calculated using the given equation [20].

Impact Energy $U=\frac{n \cdot m \cdot V^{2}}{2}$

Where, $\mathrm{n}=$ number of impacts, $\mathrm{V}=$ impact velocity and $\mathrm{m}=$ drop mass

The empirical relationship to calculate the impact energy can be given as follows,

$$
\begin{aligned}
& \mathrm{H}=\frac{g t^{2}}{2} \\
& \mathrm{~V}=\mathrm{g} \cdot \mathrm{t} \text { and } \mathrm{m}=\mathrm{W} / \mathrm{g}
\end{aligned}
$$

Where, $\mathrm{V}$ is the velocity of the hammer at impact, $\mathrm{g}$ is acceleration due to gravity and $t$ is the time required for the hammer to fall from the height $571 \mathrm{~mm}$. Substituting these equations in equation (1) then the impact energy is been calculated as shown in table 6 .

Table 6: Impact Energy test results for concrete specimens in $\mathrm{kN} . \mathrm{mm}$

\begin{tabular}{|l|l|l|}
\hline \multirow{2}{*}{ Mix } & Impact energy \\
\cline { 2 - 3 } & $\mathbf{7}$ days & 28 days \\
\hline M0 & 162.44 & 162.44 \\
\hline M1 & 121.8 & 162.44 \\
\hline M2 & 203 & 243.66 \\
\hline M3 & 182.7 & 203.05 \\
\hline
\end{tabular}

From the test results it come to know that recycled aggregates with 50\% replacement with the natural aggregates are having the high impact energy when compared to that of the normal aggregates and also when the percentage of replacement increases more than it energy absorbed starts reducing but it is higher than that of conventional mix.

\section{Conclusion}

Acetic acid treated recycled aggregates were used as partial replacement for natural aggregates to achieve strength properties and conclusion is arrived.

1. The removal of mortar attached to the recycled aggregates with $1 \%$ dosage of acetic acid solution is successful contributing that an immersion period of 1 day is sufficient determined from the test investigation of aggregates.
2. The compressive strength of conventional concrete and the recycled aggregate concrete with a replacement percentage of $50 \%$ obtains nearly similar strength.

3. The Split tensile strength of Conventional concrete is higher than recycled aggregate concrete up to $25 \%$ replacement of natural aggregate with recycled aggregate .

4. The Water absorption for concrete increases as the replacement level increases due to the some mortar present in the aggregates.

5. The Bond strength is only increased at $75 \%$ replacement level with the natural aggregates and also the bond strength tends to decrease with increase in the curing period.

6. The impact energy for recycled aggregate concrete specimens is calculated from the empirical relationship and it is denoted that $50 \%$ replacement with the natural aggregates has more impact strength further replacement level there is reduction in the impact strength.

7. Increase in dosage level of acetic acid solution may also help in increase of strength which can be checked in the further studies.

\section{References}

[1] C. Thomas, J. Setien, J.A. Polanco, P. Alaejos, M. Sanchez de Juan. Durability of Recycled aggregate Concrete. Construction and Building Materials. 40. 1054-1065(2013).

[2] MonalisaBehera, S.K. Bhattacharyya, A.K. Minocha, R. Deoliya, S. Maiti. Recycled Aggregate from C\&D waste and its use in concrete - A breakthrough towards sustainability in construction sector: A review. Construction and Building Materials. 68. 501-516(2004).

[3] Salomon M. Levy, Paulo Helene. Durability of recycled aggregates concrete: a safe way to sustainable development. 34. 19751980(2004)

[4] A. Domingo-Cabo, C. Lazaro, F. Lopez-Gayarre, M.A. SerranoLopez, P. Serna, J.O. Castano-Tabares. Creep and Shrinkage of recycled aggregate concrete. 23. 2545-2553(2009).

[5] L. Butler, J.S. West, S.L. Tighe. The effect of recycled concrete aggregate properties on the bond strength between RCA concrete and steel Reinforcement. 41. 1037-1049(2011).

[6] Abdelgadir Abbas, GholamerzaFathifazl, O. BurkanIsgor, A.G. Razaqpur, Benoit Fouriner, Simon Foo. Journal of ASTM international. 5. (2008).

[7] ASTM C 666/C 666M -03, Standard test method for resistance of concrete to rapid freezing and thawing, Annual book of ASTM standards, American society for Testing and Materials, West Conshohocken, Pennsylvania, USA, 2010.

[8] Vivian W.Y. Tam, C.M. Tam, K.N. Le. Removal of cement mortar remains from recycled aggregate using pre-soaking approaches. Resources, Conservation and Recycling. 50. 82-101(2007).

[9] Sallehan Ismail, MahyuddinRamli, Engineering properties of treated recycled concrete aggregate(RCA) for structural applications. Construction and Building materials. 44. 464476(2013).

[10] Evert Mulder, Tako P.R de Jong, LourensFeenstra. Closed Cycle Construction: An integrated process for the separation and reuse of C\&D waste. Waste Management. 27. 1408-1415(2007).

[11] J.A. Larbi, W.M.M. Heijnen, J.P. Brouwer, E. Mulder. Preliminary laboratory investigation of thermally treated recycled concrete aggregate for general use in concrete. Waste Management Series. 1 129-139(2000).

[12] Marta Sanchez de Juan, PilarAlaejos Gutierrez. Study on the influence of attached mortar content on the properties of recycled concrete aggregate. Construction and Building materials. 23. 872877(2009).

[13] Liang Wang, Jialai Wang, XinQian, Peiyuan Chen, Ying Xu, Jinxing Guo. An environmentally friendly method to improve the quality of recycled concrete aggregates. Construction and Building materials. 144. 432-441.(2017)

[14] Zine-el-abidineTahar, Tien-Tung Ngo, El HadjKadri, Adrien Bouvet, FaridDebieb, SalimaAggoun. Effect of cement and admixture on the utilization of recycled aggregates in concrete. Construction and Building materials. 149.91-102(2017).

[15] Jianzhuang Xiao, H. Falkner. Bond behaviour between recycled aggregate concrete and steel rebars. Construction and Building materials. 21. 395-401 
[16] Indian Standard 10262:2009. Concrete Mix proportioning guidelines. (First Revision). Bureau of Indian Standards.

[17] Indian Standard 5161959 Methods of Tests for strength of concrete:Bureau of Indian Standards

[18] Indian Standard 2770(Part-1) -1967. Methods of testing bond in Reinforced concrete. Pull out Test. Bureau of Indian Standards

[19] ACI Committie 544, "Measurement of properties of fiber reinforced concrete (544.2R-89)." American Concrete Institute (1989).

[20] G. Murali, A.S Santhi, G. Mohan Ganesh. Empirical relationship between the Impact energy and Compressive Strength for Fiber Reinforced Concrete. Journal of Scientific and Industrial Research. 73. 469-473(2014). 